\title{
Incidence and Predictive Factors of Latent Tuberclosis Infection amongst Personnel of Ayatollah Rouhani Hospital in Babol, 2015-2016
}

\author{
Masomeh Bayani, Mohammad Reza Hasanjani Roushan, Abdolghayoum Haji Li Doji, Arefeh \\ Babazadeh, Soheil Ebrahimpour, Mostafa Javanian
}

\section{ABSTRACT}

OBJECTIVE: The current study was designed to determine the incidence of latent TB and its predictive factors.

METHODOLOGY: This was cross-sectional prospective study. Two tuberculin skin tests (TST) were performed in $\mathbf{4 0 0}$ health care staff (HCWs) of Ayatollah Rouhani Hospital Babol over one year and during the interview Age, Sex, Occupation, History of contact with tuberculosis and BCG scars were performed. Positive skin test was considered $10 \mathrm{~mm}$; People with skin test less than $10 \mathrm{~mm}$ after one year were re-tested. An increase of more than $10 \mathrm{~mm}$ in the second test in negative PPD subjects was considered as a positive test.

RESULTS: The prevalence of latent TB was $14.7 \%$ among the 400 health workers. $71.7 \%$ were women. The average age was 32.7 years. The incidence of latent tuberculosis was $6 \%$ (18 cases): technicians had the highest incidence $(8.8 \%)$ and the nursing staff $(6.6 \%)$, while services $(2.5 \%)$ and administrative staff had the lowest incidence (0\%). Out of these 18 people, $17(94.4 \%)$ had reported a history of a patient with tuberculosis (TB) patient.

CONCLUSION: According to the results of the study, the incidence of latent tuberculosis in this center is intermediate. The most important risk factor was the work experience of more than five years. Healthcare personnel training and infection control programs must be addressed adequately.

KEYWORDS: latent tuberculosis, tuberculin skin test, medical personnel

This article may be cited as: Bayani M, Roushan MRH, Doji AHL, Babazadeh A, Ebrahimpour S, Javanian M. Incidence and Predictive Factors of Latent Tuberclosis Infection amongst Personnel of Ayatollah Rouhani Hospital in Babol, 2015-2016. J Liaquat Uni Med Health Sci. 2018;17(04):203-7. doi: 10.22442/jlumhs. 181740578

\section{INTRODUCTION}

Mycobacterium tuberculosis is the most common cause of death from infectious diseases worldwide ${ }^{1}$. Ninety five percent of tuberculosis (TB) cases occur in developing countries, and more than $75 \%$ of this population includes active age groups (15-50 years old $)^{2,3}$. Latent tuberculosis infection (LTBI) is a condition in which the patient has mycobacterium tuberculosis infection, but has no active tuberculosis disease currently, and has a positive skin test without clinical or radiological findings ${ }^{4}$. Based on the world health organization (WHO), one out of every three people suffers from latent tuberculosis infection ${ }^{5}$. Tuberculosis is an occupational illness ${ }^{6}$. Hospital personnel include physicians, nurses, attendants and other groups working in health centers are at risk for tuberculosis. Reactivation of tuberculosis in this group of people is the main cause of active or symptomatic tuberculosis. The average incidence of active tuberculosis in Iran is 50 per 100,000 people, placing this country among the countries with moderate incidence(low- and moderate-incidence (defined as an incidence rate of less than 100/100 000 per year) countries ${ }^{7}$.

Factors that increase the risk of tuberculosis infection include HIV infection, contact with tuberculosis patients, working in a nursing home or sanatorium, and traveling to endemic areas ${ }^{8,9}$. Some studies showed the increased risk of infection in health workers. Several studies indicated the history of contact with tuberculosis patients as predictive factors for TST-positive results. Some of them reported a positive TST of $12-15 \%$ and even more along with the incidence of latent infection among hospital personnel ${ }^{10,11}$. Therefore, considering the varied results of previous studies and since more attention has been paid to the prevalence of this infection in different studies, particularly in Iran, the present study was conducted to determine the incidence of latent tuberculosis infection and its predictive factors among the personnel of Ayatollah Rouhani Hospital in Babol. 


\section{METHODOLOGY}

This prospective cross-sectional study was designed in 500-bed Ayatollah Rouhani Hospital in Babol in Mazandaran province. In a plan regulated by the Hospital Infection Control Committee from March 2015 until March 2016, 625 personnel working in various departments were selected to be included in the study (Figure 1). 225 people were excluded from the study for various reasons, including the history of active tuberculosis in the past, immunosuppressive drugs, unwillingness to cooperate or history of positive TST. The standard TST method was performed for 400 personnel. In addition, these personnel were from different sections of the hospital, including nursing staff (nurses, midwives, and health care providers), service providers (secretary, nutritionist, cleaner, and laundry), technicians (labs, radiology, pathology, physiotherapy). Various data such as age, gender, personnel category, history of contact with tuberculosis (according to staff records during hospital employment), having BCG scar (based on direct observation), the period of employment in the hospital, the place of residence, yearly income, and the level of education were entered into pre-prepared questionnaires. At the beginning of the study, the personnel underwent clinical examination, and in case of having a history or clinical symptom of tuberculosis, they were examined regarding to active tuberculosis, in which no case of active tuberculosis was registered. Then, a trained nurse performed a tuberculin skin test through subcutaneous injection of 10 units $(0.1 \mathrm{ml})$ of standard PPD vial in the middle of the forearm according to international standards of WHO and through Mantoux technique and the result was read 72 hours after the test (in duration diameter was measured according to the millimeter). The stiffness more than $10 \mathrm{~mm}$ was considered to be positive ${ }^{12}$.The test was repeated after one year in personnel who had a negative primary test result. Moreover, BCG vaccination may affect the TST results, maximum in the first five years after vaccination, and these individuals were adults; thus routine BCG vaccination in our country was implemented in neonatal periods. Data were analyzed using SPSS16 software. The Kolmogorov-Smirnov test was used to examine the normal distribution of data. The one-way ANOVA test was used to compare the different parts, and regression test was used to determine the risk factors for a positive tuberculin test. $\mathrm{P} \leq 0.05$ was considered significant.

\section{RESULTS}

In this study, of the total 400 patients who were included in the study and underwent TST, the prevalence of latent tuberculosis infection was $14.7 \%$. Of the 341 patients who had negative TST in the first visit, 41 patients were excluded due to the unwillingness to cooperate and perform subsequent TST tests. Three hundred patients underwent TST test at their second visit one year later, among which 18 patients $(6 \%)$ had positive TST in the second visit. In this study, the relationship between TST conversion and various variables was investigated. The presences of BCG scar, a history of previous exposure to active TB patient, and gender did not effect on TST conversion $(P \leq 0.05)$.

Of all studied patients, 215 patients $(71.7 \%)$ were female, and 85 patients (28.3\%) were male. The mean age of the subjects was 32.7 years. Moreover, in examining the relationship between the type of occupational activity of the personnel, nurses had the highest frequency of positive TST. Laboratory

\section{FIGURE I: SCREENING ALGORITHM AND PATIENTS' ENTRY INTO THE STUDY}

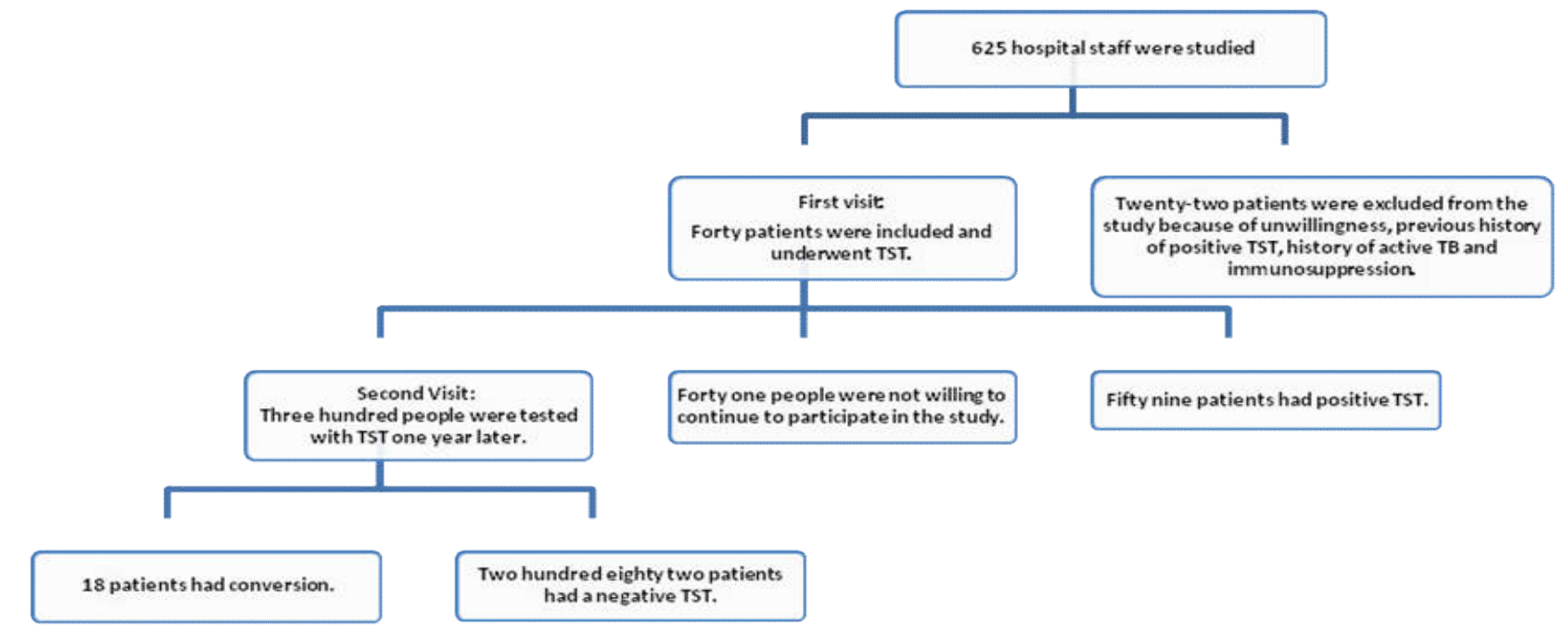


Masomeh Bayani, Mohammad Reza Hasanjani Roushan, Abdolghayoum Haji Li Doji, Arefeh Babazadeh, Soheil Ebrahimpour, Mostafa Javanian

technicians and pathologists were in the following ranks, but this difference was not statistically significant $(P>0.05)$.

According to the data in Table $\mathrm{I}$, the chance of conversion increased as the employment period increased; with an employment period more than 15 years, the chance of conversion increased significantly $(p=0.03)$.

Furthermore, the chance of conversion in people working in the health care system is 7.95 times more than non-medical staff. However, this difference was not statistically significant. In studying the personnel activity area, personnel working in the neurology department and then the infection department had the highest conversion after one year.

\section{DISCUSSION}

In this study, the prevalence of tuberculosis in 400 cases was $14.7 \%$, and its incidence was $6 \%$, and among patients with LTBI, $94.4 \%$ of cases had a history of contact with TB patients. According to the World Health Organization statistics in 2015, the incidence of LTBI in the general population of Iran was reported to be 16 per 100,000 people $^{13}$. Considering that health care providers are at high risk for being exposed to TB and as a result, the occurrence of LTBI, and since the present study was conducted among this population, high incidence of this disease compared to the general population is expected. On the other hand, these results are consistent with studies conducted in

\section{TABLE I:}

INVESTIGATING THE RELATIONSHIP BETWEEN DIFFERENT VARIABLES AND THE TST RESULT

\begin{tabular}{|c|c|c|c|c|c|c|}
\hline \multicolumn{2}{|c|}{ Variable } & \multirow{2}{*}{\begin{tabular}{|l|}
$\begin{array}{c}\text { Negative test result } \\
\text { Number (\%) }\end{array}$ \\
$77(27.3)$ \\
\end{tabular}} & \multirow{2}{*}{\begin{tabular}{|c|c|}
\multicolumn{1}{c}{ Positive test } \\
result Number (\%) \\
$6(33.3)$
\end{tabular}} & \multirow{2}{*}{\begin{tabular}{|l|}
$\begin{array}{c}\text { Risk ratio }(95 \% \\
\mathrm{CI})\end{array}$ \\
1
\end{tabular}} & \multicolumn{2}{|c|}{$P$ - value } \\
\hline \multirow{3}{*}{ Age } & $20-30$ & & & & - & \multirow{3}{*}{0.25} \\
\hline & $30-40$ & $153(54.3)$ & $9(50)$ & $0.44(0.01,190)$ & 0.35 & \\
\hline & $40 \geq$ & $52(18.4)$ & $3(16.7)$ & $0.17(0.02,1.42)$ & 0.18 & \\
\hline \multirow{4}{*}{ Occupation } & Nurse & $197(69.8)$ & $14(77.79)$ & 1 & - & \multirow{4}{*}{0.2} \\
\hline & Technician & $31(11)$ & $3(16.7)$ & $1.99(0.46,67.8)$ & 0.35 & \\
\hline & Services & $39(13.8)$ & $1(5.6)$ & $0.12(0.005,2.47)$ & 0.18 & \\
\hline & Administrative & 15 & 0 & $0(0-21.8)$ & 0.48 & \\
\hline \multirow{3}{*}{ Education } & Diploma & $38(1.5)$ & 2 (11.1) & 1 & - & \multirow{3}{*}{0.78} \\
\hline & Associate degree & 25 (8.9) & $1(5.9)$ & $0.45(0.03,6.13)$ & 0.55 & \\
\hline & $\begin{array}{l}\text { Bachelor's degree } \\
\text { and higher }\end{array}$ & $219(77.7)$ & $15(38.3)$ & $0.99(5.97,0.17)$ & 0.99 & \\
\hline \multirow{4}{*}{$\begin{array}{l}\text { Employment } \\
\text { period }\end{array}$} & $1-5$ & 59 (20.9) & $3(16.7)$ & 1 & - & \multirow{4}{*}{0.22} \\
\hline & $5-10$ & $160(56.7)$ & $10(55.6)$ & $2.62(0.45,15.19)$ & 0.28 & \\
\hline & $10-15$ & 39 (13.8) & $2(11.1)$ & $3.65(0.34,38.7)$ & 0.28 & \\
\hline & $15 \geq$ & $24(8.5)$ & $3(16.7)$ & $12.29(1.14,13.98)$ & 0.03 & \\
\hline \multirow{2}{*}{$\begin{array}{l}\text { Contact with TB } \\
\text { patients }\end{array}$} & No & $13(4.6)$ & $1(5.6)$ & 1 & \multirow{2}{*}{\multicolumn{2}{|c|}{0.81}} \\
\hline & Yes & $269(95.4)$ & $17(94.4)$ & $0.75(0.07,1.8)$ & & \\
\hline \multirow{2}{*}{ BCG } & No & $17(6)$ & $2(11.1)$ & 1 & \multirow{2}{*}{\multicolumn{2}{|c|}{0.43}} \\
\hline & Yes & $265(94)$ & $16(88.9)$ & $0.51(0.09,2.75)$ & & \\
\hline \multirow{2}{*}{ Gender } & Male & $79(28)$ & $6(3.33)$ & $1.44(0.02,88.78)$ & \multirow{2}{*}{\multicolumn{2}{|c|}{0.86}} \\
\hline & Female & $203(72)$ & $12(66.7)$ & 1 & & \\
\hline \multirow{2}{*}{$\begin{array}{l}\text { Place of } \\
\text { residence }\end{array}$} & City & $203(72)$ & $12(66.7)$ & 1 & \multirow{2}{*}{\multicolumn{2}{|c|}{0.88}} \\
\hline & Village & $79(28)$ & $6(33.3)$ & $1.37(0.02,83.78)$ & & \\
\hline \multirow{2}{*}{ Section } & Therapeutic & $272(96.5)$ & $17(94.4)$ & 1 & \multirow{2}{*}{\multicolumn{2}{|c|}{0.19}} \\
\hline & Non-therapeutic & $10(3.5)$ & $1(5.6)$ & $7.95(0.34,183.02)$ & & \\
\hline
\end{tabular}


endemic countries. In addition, the worldwide prevalence of LTBI among health care workers was reported to be $1.87 \%$ to $47 \%{ }^{14}$.

However, the prevalence of LTBI in the present study was $14.7 \%$, which was significantly lower than high risk health care worker populations in Thailand $(63 \%)$, Uganda (57\%), and the Netherlands (41\%), which is justifiable due to the fact that Iran is an intermediate region in terms of endemicity ${ }^{15,16}$. The results of the present study showed that the incidence of LTBI in technicians $(1.82 \%)$ and nurses $(6.63 \%)$ was higher than other hospital personnel. Among nurses, the most frequent incidence was reported in nurses in the neurology department and then in the infection department. As can be observed in similar studies, LTBI can be seen as an occupational illness that is more likely to be found in occupations with higher exposure to TB patients. In the case of the neurology department, which may seem to be unlikely to have high incidence of LTBI in its personnel at the first glance, it can be said that it is one of the areas where the hospitalization of disabled patients and suctioning of respiratory secretions and respiratory physiotherapy is highly frequent and, thus, this event is not far off in this department, another evidence that shows LTBI is an occupational illness is that its prevalence increases as occupational experience increases in high-risk occupations. According to the present study, the chance of conversion increased significantly after more than 15 years of occupational experience. According to this study, as education level increased, the prevalence of this disease decreased, which reflects the effect of education level on the observance of the principles of infection control and disease prevention ${ }^{17,18}$.

Moreover, in studying the positive TST cases, no active tuberculosis case was reported. Although there is not enough data regarding nosocomial tuberculosis transmission in Iran, it seems that health care workers are lower in age and underlying illnesses than the general population that is affected bytuberculosis ${ }^{19}$. Therefore, the chance of active tuberculosis in these people is more moderate.

\section{CONCLUSION}

According to the results of this study, the incidence of LTBI in health care workers of this hospital was moderate. The most important risk factor was their more extended working experience. It was also observed that BCG vaccination did not affect the TST result. Therefore, it is recommended that during recruitment, especially in high-risk areas for exposure to tuberculosis (infectious or neurological),a primary TST should be performed and periodically (every year) evaluated in regard with the conversion. In converted TST cases, after rule out of active TB, treatment should be implemented for LTB.

Also, health personnel should be trained regarding the principles of infection control and periodic assessment of compliance with these principles.

\section{ACKNOWLEDGMENTS}

The authors express their appreciation to personnel of Ayatollah Rouhani educational and therapeutic center, Babol, Iran.

\section{Conflict of interest}

All of authors declare no conflict of interest.

\section{REFRENCES}

1. Savadkoohi R, Edraki M, Mehdipour S. Pulmonary Tuberculosis in a 2.5 year old child wirh impression of bird flu. JBUMS 2007; 9(4): 71-75.

2. Taghizade Moghaddam H, Emami Moghadam Z, Khademi G, Bahreini A, Saeidi M. Tuberculosis: Past, Present and Future. Int J Pediatrics 2016; 4 (1): 1243-54. doi: 10.22038/ ijp.2016. 6266

3. López Ávalos GG, Prado Montes de Oca E. Classic and New Diagnostic Approaches to Childhood Tuberculosis. J Trop Med 2012; 2012: 818219. doi: 10.1155/2012/818219

4. Zenner D, Beer N, Harris RJ, Lipman MC, Stagg $H R$, van der Werf MJ. Treatment of Latent Tuberculosis Infection: An Updated Network Meta -analysis. Ann Intern Med 2017; 167(4): 248-55. doi: 10.7326/M17-0609.

5. Zumla A, George A, Sharma V, Herbert RH, Baroness Masham of Ilton, Oxley A, et al. The WHO 2014 global tuberculosis report-further to go. Lancet Glob Health 2015; 3(1): e10-e12. doi: $10.1016 / S 2214-109 X(14) 70361-4$.

6. Mendoza-Ticona A. Tuberculosis as occupational disease. Rev Peru Med Exp Salud Publica 2012; 29(2): 232-6.

7. Haghdoost AA, Afshari M, Baneshi MR, Gouya MM, Nasehi M, Movahednia M. Estimating the Annual Risk of Tuberculosis Infection and Disease in Southeast of Iran Using the Bayesian Mixture Method. Iran Red Crescent Med J 2014; 16(9): e15308. doi: 10.5812/ircmj.15308

8. Narasimhan P, Wood J, Macintyre CR, Mathai D. Risk factors for tuberculosis. Pulm Med 2013; 2013: 828939. doi: 10.1155/2013/828939.

9. Méda ZC, Sombié I, Sanon OWC, Maré D, Morisky DE, Chen Y-MA. Risk Factors of Tuberculosis Infection Among HIVIAIDS Patients in Burkina Faso. AIDS Res Hum Retroviruses 2013; 29(7): 1045-55. doi: 10.1089/aid.2012.0239.

10. Kunst $\mathrm{H}$. Diagnosis of latent tuberculosis infection: The potential role of new technologies. Respir Med 2006; 100(12): 2098-106. 
